Rev Biomed 1999; 10:1-6.

\title{
Análisis microbiológico de algunas infusiones de hierbas medicinales.
}

María L. Arias ${ }^{1}$, Carolina Chaves ${ }^{1}$, Luis Diego Alfaro².

${ }^{1}$ Facultad de Microbiología, Universidad de Costa Rica, ${ }^{2}$ Caja Costarricense de Seguro Social. San José, Costa Rica, C.A.

RESUMEN.

Introducción.La menta (Mentha piperitd) y el anís de estrella (Illicium verum) representan algunas de las plantas que se han procesado y comercializado con fines terapéuticos entre otros. A pesar de las propiedades que poseen las hierbas medicinales, no se puede descartar la presencia de componentes químicos dañinos a la salud o bien agentes microbiológicos que pueden generar serios problemas de salud en el consumidor. El objetivo de este estudio fue evaluar la calidad bacteriológica de dos de las más consumidas en Costa Rica: menta y anís de estrella. Así mismo, se pretendió determinar el efecto de diferentes tipos de tratamiento térmico sobre la carga bacteriológica de las infusiones. Material y métodos. se analizó el recuento total aerobio, recuento de coliformes totales, recuento de coliformes fecales y recuento de Pseudomonas aeruginosa de 24 muestras de infusión de menta y 24 muestras de infusión de anís de estrella, siguiendo la metodología descrita por Vanderzant y Splittstoesser. Además se evaluó la sobrevivencia bacteriana al preparar la infusión de hierbas me- diante el método convencional de cocimiento, hervida o en microondas.

Resultados. Los resultados obtenidos demuestran que el $85.7 \%$ de las muestras de la infusión de menta y $8.3 \%$ de las de anís presentan recuentos totales que sobrepasan la norma internacional de la OMS. El 100\% de las muestras de menta incumplieron esta norma para coliformes totales y el $41.7 \%$ para coliformes fecales; contrario al anís de estrella, en que el $100 \%$ de las muestras cumple con la norma propuesta. Los niveles encontrados de Pseudomonas aeruginosa en ambos tipos de infusión fueron mayores a la tolerancia establecida por la USP (United States Pharmacopeia). Los resultados de sobrevivencia demuestran que tanto el método convencional como el microondas no logran eliminar todas las bacterias presentes en las infusiones de hierbas.

Discusión. Los resultados de este estudio evidencian serias deficiencias en la calidad microbiológica en las infusiones de hierbas medicinales, por lo cual es importante desarrollar reglamentos con respecto a los controles que deben efectuarse a éstas de

Solicitud de sobretiros: María Laura Arias E. Facultad de Microbiología, Universidad de Costa Rica. San José, Costa Rica, C.A. Recibido el 23/Abril/1998. Aceptado para publicación el 30/Junio/1998. 
ML Arias, C Chaves, LD Alfaro.

manera que no representen un riesgo para la salud de los consumidores. (Rev Biomed 1999; 10:1-6)

Palabras clave: Medicina herbolaria, calidad bacteriológica, medicina tradicional.

\section{SUMMARY.}

Microbiological analysis of some herbal infusions used as medicines.

Introduction. Mint (Mentha piperita) and star anise (Illicium verum) represent some of the plants that have been processed and commercialized for therapeutic reasons. As well as the curing properties associated with these medicinal herbs, they may also present chemical components or microbiological agents that can create health problems to the consumers. The aim of this study was to evaluate the bacteriological quality of two of the medicinal herbs most commonly used in Costa Rica: mint and star anise. At the same time, we pretended to determine the effect of different thermic treatments over the bacteriological load of the infusions.

Material and methods. the total aerobic plate count, total and fecal coliforms counts and Pseudomonas aeruginosa count was determined in 24 samples of mint infusion and 24 samples of star anise infusion, according to the methodology described by Vanderzant \& Splittstoesser. The bacterial survival rate was also evaluated, when the infusions were prepared either by the conventional method, in microwave oven or by boiling.

Results. the results obtained show that $85.7 \%$ of the mint infusion samples and $8.3 \%$ of the star anise infusion samples presented total aerobic plate counts over the international norm established by WHO. $100 \%$ of the mint samples did not satisfy the norm for total coliforms, and $41.7 \%$ for fecal coliforms. $100 \%$ of star anise samples did satisfy the proposed norm.

Pseudomonas aeruginosa was found in levels above the tolerance established by the USP (United States Pharmacopeia) in both samples. Survival results showed that neither the conventional or microwave treatments eliminated all the bacteria present in herbal infusions.

Discussion. The results of this study showed poor microbiological quality of the herbal infusions used as medicines. Therefore, it is important to develop norms that should be applied to the controls, so that they will not represent a health risk to consumers. (Rev Biomed 1999; 10:1-6)

Key words: Herborist medicine, bacteriological quality, traditional medicine.

\section{INTRODUCCIÓN.}

Desde la aparición del hombre sobre la tierra, la naturaleza ha representado un medio para que éste consiga alivio, curación o prevención de los malestares que afectan su organismo, esto a través de plantas, derivados de animales y de otras sustancias de índole diversa (1). En la actualidad, de las quinientas mil especies de plantas conocidas, únicamente una pequeña parte de éstas han sido investigadas fitoquímicamente y una fracción aún menor, ha sido sometida a pruebas de actividad biológica o farmacológica (2). No obstante, la industria farmacéutica explota este recurso, dado que la producción de medicinas sigue dependiendo en buena parte del uso de plantas como materia prima (3).

La menta (Mentha piperita) y el anís de estrella (Illicium verum) representan algunos ejemplos de plantas que han sido procesadas y comercializadas con fines terapéuticos. A la menta se le atribuyen acciones antiespasmódicas y carminativas y se recomienda en dispepsia, flatulencia y cólico (4). Así mismo, posee un amplio uso en el tratamiento popular de resfríos, histeria y desórdenes nerviosos (5).

Por otro lado, al anís de estrella se le atribuyen características digestivas. Se usa también como carminativo, estimulante, diurético y antireumático (5).

A pesar de las propiedades medicinales que

\section{Revista Biomédica}




\section{Bacteriología de infusiones herbolarias.}

poseen las hierbas, no se puede descartar la presencia de componentes químicos propios de su naturaleza que puedan generar deterioro en la salud del consumidor. Los nitratos, oxalatos, taninos y glicósidos cianógenos pueden modificar el metabolismo normal del individuo. Por otro lado, los agentes microbiológicos provenientes de las áreas de cultivo y del deficiente manejo postcosecha de las hierbas pueden originar serios problemas gastrointestinales en el comensal.

En Costa Rica, al igual que en varios países del continente, la corriente naturista ha venido tomando fuerza en las últimos años, pues se ha retomado el pensamiento que la Medicina encontró en la naturaleza la mejor fuente de curación (2). Ante esta situación, y dado que cada vez es más frecuente el uso de infusiones de hierbas medicinales, este estudio se propuso evaluar la calidad bacteriológica de dos de las más consumidas en Costa Rica: menta y anís de estrella. Así mismo, se pretende determinar el efecto sobre la carga bacteriológica de los deferentes tipos de preparación de las infusiones.

\section{MATERIAL Y MÉTODOS.}

Durante el segundo semestre de 1997 y primero de 1998, se analizó en el Laboratorio de Microbiología de Alimentos, Universidad de Costa Rica, 24 muestras de infusión de menta y 24 muestras de infusión de anís de estrella, provenientes de 16 lotes diferentes, adquiridos al azar en supermercados del Area Metropolitana de San José, Costa Rica. Los análisis realizados incluyeron el recuento total aerobio, recuento de coliformes totales, recuento de coliformes fecales y recuento de Pseudomonas aeruginosa siguiendo la metodología descrita por Vanderzant y Splittstoesser (6). Se utilizó la técnica de recuento en placa dados los altos recuentos obtenidos en investigaciones previas (7).

Brevemente, se prepararon diluciones decimales a partir de $25 \mathrm{~g}$ de cada una de las muestras de producto comercial, utilizando agua peptonada estéril $0.1 \%$. A partir de cada dilución se realizaron, por duplicado, los análisis mencionados.

El recuento total aerobio fue determinado utilizando agar Standard + TTC (2,3,5-cloruro de trifenil tetrazolium) $0.1 \%$ luego de incubar a $37^{\circ} \mathrm{C}$ por 48 horas. Para el recuento de coliformes totales y fecales, se utilizaron las mismas diluciones y agar bilis rojo violeta, el cual fue incubado $48 \mathrm{~h}$ a $37^{\circ} \mathrm{C}$ para el recuento de coliformes totales y $24 \mathrm{~h}$ a $44.5^{\circ} \mathrm{C}$ para el recuento de coliformes fecales. El recuento de P. aeruginosa fue determinado utilizando agar $\mathrm{F}$ incubado a $42^{\circ} \mathrm{C}$. La identificación posterior fue realizada con base en pruebas bioquímicas (TSI, fermentación-utilización de azúcares, pruebas de descarboxilación de lisina, arginina y ornitina, oxidasa, catalasa, etc.).

Para el estudio de sobrevivencia, se evaluó el recuento total inicial de una mezcla de infusión de hierbas (menta o anís de estrella) utilizando agar Standard + TTC, según el procedimiento descrito anteriormente. Se dividió esta mezcla en subgrupos, los cuales fueron sometidos a diferentes tratamientos térmicos:

a. Convencional: se agregó $25 \mathrm{~g}$ de la mezcla a $225 \mathrm{~mL}$ de agua a $60^{\circ} \mathrm{C}$ (temperatura constante) y se dejó en ésta por $1 \mathrm{~min}$, al cabo del cual se determinó el recuento total aerobio. Igual procedimiento se utilizó dejando la mezcla por $2 \mathrm{~min}$ y por $3 \mathrm{~min}$.

b. Microonda: se agregó $25 \mathrm{~g}$ de la mezcla a $225 \mathrm{~mL}$ de agua, los cuales fueron tratados en horno de microonda, $100 \%$ de poder, durante 1 min, al cabo del cual se evaluó el recuento total aerobio. Igual procedimiento se utilizó tratando la mezcla por 2 min y 3 min en el horno de microonda.

c. Ebullición: se agregó $25 \mathrm{~g}$ de la mezcla a $225 \mathrm{~mL}$ de agua en ebullición, los cuales fueron mantenidos de igual forma durante $1 \mathrm{~min}$, tiempo en que se determinó en recuento total aerobio. Igual procedimiento se utilizó dejando ebullir la mezcla por 2 min y $3 \mathrm{~min}$.

Vol. 10/No. 1/Enero-Marzo, 1999 
ML Arias, C Chaves, LD Alfaro.

\section{RESULTADOS.}

Los resultados obtenidos demuestran que el $85.7 \%$ de las muestras de la infusión de menta presentan recuentos totales que sobrepasan la norma internacional de la OMS, la cual estipula que el recuento total aerobio debe ser inferior a 105 UFC g (8). Una situación diferente se observó en las muestras de anís de estrella, pues solamente el 8.3\% excedieron la norma.

La normativa de la OMS para coliformes totales y fecales en infusión de hierbas permite hasta $103 \mathrm{UFC} / \mathrm{g}$. El 100\% de las muestras de menta incumplieron esta norma para coliformes totales y el $41.7 \%$ para coliformes fecales; contrario al anís de estrella, en que el $100 \%$ de las muestras cumple con la norma propuesta.

Los niveles encontrados de Pseudomonas aeruginosa en ambos tipos de infusión fueron mayores a la tolerancia establecida por la USP (United States Pharmacopeia) (9).

Según estas divergencias con las normas es-

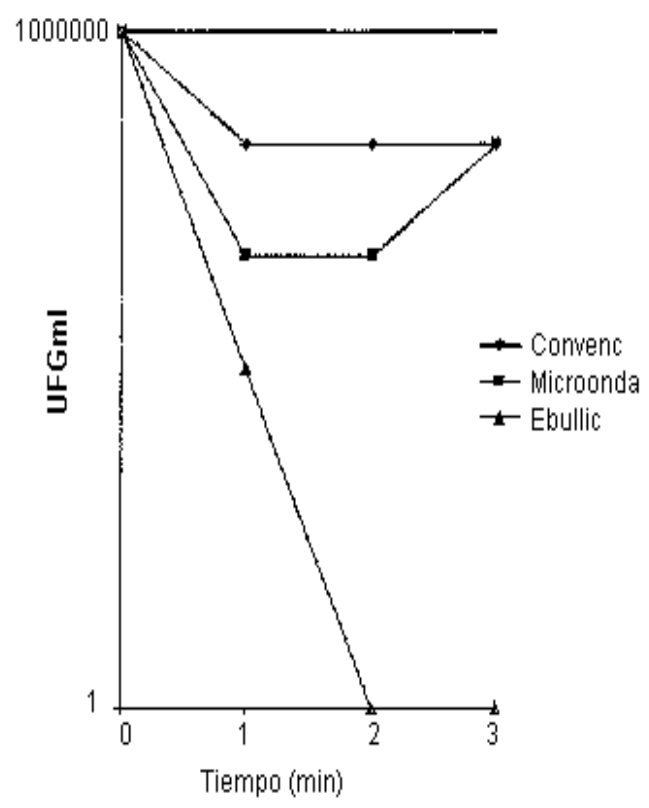

Figura 1.- Sobrevivencia de las bacterias según el tipo de tratamiento. tablecidas, $6 / 8$ lotes de menta y $2 / 8$ de anís de estrella son inaceptables para consumo humano. El análisis de supervivencia en la modalidad convencional demuestra una disminución en el número de bacterias de únicamente un logaritmo, después de 3 min de tratamiento (figura 1 ).

$\mathrm{Al}$ analizar la supervivencia de bacterias en las infusiones elaboradas en microonda, se nota un descenso de dos logaritmos en el recuento total aerobio en el primer minuto de tratamiento, seguido por un aumento en la población en los minutos subsiguientes, llegando a niveles superiores a los iniciales.

$\mathrm{Al}$ analizar la supervivencia en infusiones elaboradas por ebullición, durante el primer minuto de tratamiento se observa un descenso de 3 logaritmos en el recuento total, seguido por la desaparición total de bacterias después de 2 min de tratamiento térmico.

\section{DISCUSIÓN.}

La contaminación de las infusiones de hierbas medicinales proviene, al igual que en otras hierbas y especias, a partir de la forma y sitio donde se cultivan o de su procesamiento. Este procesamiento incluye el secado, el cual puede realizarse de forma artesanal, al aire libre, o bien utilizando calor, pero a una temperatura inferior a $\operatorname{los} 30^{\circ} \mathrm{C}$ con el fin de que las plantas y hierbas conserven sus características organolépticas $(10,11)$.

La presencia de microorganismos contaminantes en las infusiones de hierbas medicinales representa un riesgo potencial para la salud del consumidor, más si en su preparación se utilizan condiciones que permitan la sobrevivencia de estos.

Las muestras de infusión de menta y anís de estrella evaluadas mostraron recuentos totales superiores a la norma establecida, situación igual a la reportada por Schiller, Kuntscher y Wolff (12) en materias primas de origen vegetal.

El recuento de coliformes totales es un indicador de higiene. Ante esto, es evidente suponer el deficiente manejo de la menta durante la pro-

\section{Revista Biomédica}


Bacteriología de infusiones herbolarias.

ducción. Una situación diferente podría asumirse con la infusión de anís, sin embargo, no puede descartarse que los bajos recuentos totales sean efecto del anetol, componente principal del anís de estrella sobre el crecimiento bacteriano. El anetol (1metoxi-4-(1-propinil)benceno) es un alcohol de alta solubilidad en compuestos orgánicos por lo que podría afectar la pared o membrana externa de las bacterias (13).

Por otro lado, la presencia de coliformes fecales en las muestras evidencia la posibilidad de que estén presentes otros agentes etiológicos de infecciones para el ser humano, tales como Escherichia coli, Shigella y Salmonella entre otros. Esta contaminación puede originarse a partir del riego con aguas negras, inadecuado almancenamiento o contaminación post-proceso, tal y como ha sido reportado por otros investigadores en drogas de uso popular (tilo, romero, linaza, canela en polvo, etc. (14)

El alto porcentaje de positividad por Pseudomonas sp., especialmente en el infusión de menta, pone de manifiesto un riesgo potencial para la salud de personas con algún tipo de compromiso inmunológico. Aun cuando esta bacteria se encuentra naturalmente en suelos, aguas; diversos autores la han asociado con infecciones oportunistas, y en diferentes estudios ha sido aislada a partir de alimentos en hospitales, cantinas y escuelas (15), de las soluciones de alimentación parenteral (16) y de productos farmacéuticos de uso oral y tópico $(17,18)$.

Es típico suponer que el tratamiento térmico reducirá cualquier riesgo que represente para el consumidor la ingesta de un producto crudo. Los resultados obtenidos en los estudios de supervivencia demuestran que al preparar estas infusiones por ebullición, se asegura una disminución importante de la carga microbiológica. No obstante, esto no es cierto para aquellas infusiones que sean preparadas por el método convencional o en horno de microonda, donde los niveles de bacterias bajan, pero no lo suficiente como para que las muestras alcancen valores aceptables. Por otro lado, el tratamiento térmico puede favorecer levemente el aumento en el número de microorganismo, tal como se observó en el tratamiento con microondas. Esto ocurre por la germinación de esporas sobrevivientes, tal y como ha sido descrito por diferentes autores $(19,20)$.

Los resultados de este estudio evidencian serias deficiencias en la calidad microbiológica en las infusiones de hierbas medicinales, por lo cual es importante desarrollar reglamentos con respecto a los controles que deben efectuarse a éstas de manera que no representen un riesgo para la salud de los consumidores. También, es importante fomentar la instauración del Sistema de Riesgos y Puntos Críticos de Control (HACCP) en la manufactura de este tipo de productos, sobre todo tomando en cuenta la incapacidad de aplicar un tratamiento térmico superior a $\operatorname{los} 30^{\circ} \mathrm{C}$ en aras de mantener las características organolépticas y la integridad de los principios activos responsables de las propiedades medicinales de las hierbas.

\section{REFERENCIAS.}

1.- Nuñez E. Plantas medicinales de Costa Rica y su folcore. 2 ed. San José: Universidad de Costa Rica; 1978. p. 318.

2.- Craker LE, Simon JE. Herbs, spices and medicinal plants: recent advances in botany, horticulture and pharmacology. 1 ${ }^{a}$. Ed. San Luis: Oryx Press; 1986. p. 166.

3.- Vargas S. Plantas Medicinales. $3^{\mathrm{a}}$ ed. San José: Grafo Print S.A.; vol. 1. 1993. p. 61.

4.- Claus E, Tyler V. Farmacognosia. $6^{\mathrm{a}}$ ed. Buenos Aires: Editorial Librería El Ateneo; 1968. p. 198.

5.- Grieve M. A modern herbal. Inc. Nueva York: Dover Publications; 1971. vol I y II. p. 543.

6.- Vanderzant C, Splittstoesser D. Compendium of methods for the microbiological examination of foods. Washington: APHA; 1992. p. 317.

7.- Atán J, Valenciano L. Identificación de algunos compuestos tóxicos y análisis microbiológico de plantas medicinales empacadas para el consumo humano. (Tesis). San José, Costa Rica: Universidad de Costa Rica. 1996.

Vol. 10/No. 1/Enero-Marzo, 1999 


\section{Arias, C Chaves, LD Alfaro.}

8.- Organización Mundial de la Salud. Manual de resoluciones de la Asamblea Mundial de Salud y del Consejo Ejecutivo. $3^{\text {a }}$ ed. Ginebra OMS; 1992. p. 147.

9.- Anonymous. United States Pharmacopeia. USP XXI.N.F. 21 a ed. Convention Inc., USA. 1985. p. 1683.

10.- Speck M. Compendium of methods for the microbiological examination of foods. 2d ed. Washington, D.C.: American Public Health Association, Inc.; 1984. p. 62-76.

11.- Owuor P, Obanda M. The impact of withering temperature on black tea quality. J Sci Food Agric 1996; 70: $288-92$.

12.- Schiller Y, Kuntscher H, Wolff A. Microbiology assays. Appl Microbiol 1968; 16: 82.

13.- Tietz N. Fundamentals of Clinical chemistry. 2nd ed. Philadelphia: WB Sauders Co.; 1982.

14.- Marín AM. Contaminación microbiológica de algunas drogas de uso popular. Tesis. San José: Universidad de Costa Rica; 1972.

15.- Shooter R, Faiers M, Cooke M, Breaden A, O’Farrel $\mathrm{S}$. Isolation of Escherichia coli, Pseudomonas aeruginosa and Klebsiella from food in hospital, canteens and schools. Lancet 1971; 21:390-2.

16.- Oie S, Kamiya A, Hironaga K, Koshiro A. Microbial contamination of enteral feeding solution and its prevention. Am J Infect Control 1992; 20: 202-5.
17.- Esquivel R, Bedoya S, Marím A. Contaminación microbiológica de productos farmacéuticos para uso oral. Rev Ciencias Farmacéuticas 1974; 2:79-89.

18.- Esquivel R, López D, Meneses L. Contaminación microbiológica de productos farmacéuticos para uso tópico. Rev Ciencias Farmacéuticas 1974; 2:90-7.

19.- Craven SE. Growth and sporulation of Clostridium perfringens in foods. Food Tech 1980; 34: 80-6.

20.- Wright-Rudolph L, Walker HW, Parish JR. Survival of Clostridium perfringens and aerobic bacteria in ground beef patties during microwave and confectional cookery. $\mathbf{J}$ Food Prot 1984; 49: 203-6.

\section{Revista Biomédica}

